H. RöthlisBerger: The transient ice flow when a cavity is forming, with the flow vectors pointing away from the rock surface at an angle, looks very promising for providing a process of plucking. Although it is unlikely that the rock will adhere firmly to the ice, there is a possibility that the water pressure might act on the lower side of a scaled-off rock slab, which might then be moved together with the ice.

IKEN: In the following I am referring to the sinusoidal bed of the model: When water under pressure can penetrate from subglacial channels to the lee sides of the bedrock waves, the pressure will be increased at the centres of the lee-sides, thus lowering the pressure-melting temperature there. However, at the edges of the lee sides, i.e. near the wave crests and valleys, the pressure will be abruptly reduced when transient ice flow causing cavity formation starts. In these zones, therefore, rock fragments will freeze to the glacier completing the plucking mechanism which you suggested.

\title{
TRANSIENT WATER FLOW IN SUBGLACIAL GHANNELS
}

\author{
By William St Lawrence
}

(U.S. Army Cold Regions Research and Engineering Laboratory, Hanover, New Hampshire 03755 , U.S.A.)

and ANTHONy QAMAR

(Department of Geology, University of Montana, Missoula, Montana 5980 I, U.S.A.)

Abstract. A hydraulic mechanism is postulated as the source of certain low-frequency $(\mathrm{I}-5 \mathrm{~Hz})$ seismic signals that are recorded in the vicinity of temperate glaciers. To illustrate that the mechanism is a plausible seismic source, the equations of motion and continuity for transient flow in a subglacial conduit are developed. The solution to these equations is obtained for the case of the flow of water being terminated in a glacial conduit. Using reasonable values of physical parameters taken from the literature, the displacement of the conduit walls is determined as a function of time and distance along the tunnel. The spectral character of the proposed source and the period of time over which it operates is compared with seismic records of typical type II signals. The agreement in terms of these parameters is good.

To further examine the validity of the proposed seismic source a preliminary energy calculation is made which demonstrates that the proposed mechanism is energetically reasonable. Evidence of hydraulically generated seismic waves from a dam site is introduced to support the theory of a hydraulic source.

Based on the evidence presented, it is suggested that the flow of water from glaciers is modulated by an internal flow regime that is intermittent in time and space.

The substance of this paper is included in a report by the present authors entitled "Hydraulic transients: a seismic source in volcanoes and glaciers", published in Science, Vol. 203 , No. $43^{8}$ i, 1979, p. $654^{-56}$. 


\section{DISCUSSION}

H. Röthlisberger: The shut-off of a channel has probably been observed by us, though only once during several weeks of continuous recordings of piezometric water pressure. The question is how to explain such an event. Plugging by sediments is one possible mechanism, faulting in the ice another. In the case of a much more frequently occurring disturbance of the water flow in a main drainage conduit, entrapped air may play the key role.

W. St LAWREnce: In our presentation we used the example of the flow being terminated in the conduit as a means of demonstrating the nature of the seismic source. In addition to generating hydraulic transients while terminating the flow they can also generate when the flow is initiated and when certain conditions for self-excited resonance are present. A familiar example of self-excited resonances is the steady-state vibration that may be produced in home piping systems when a valve (faucet) is turned to a certain setting. In a glacial conduit we would expect this condition to be self destroying. The conditions you suggest such as faulting, plugging by sediments, and entrapped air in the conduits, may also produce seismically detectable signals.

J. W. Clough: In your example, the frequency $f$ of the seismic wave was inversely proportional to the pipe length $L, f=\alpha / 4 L$. Since $f$ is quite constant, and factors influencing $\alpha$ constrained, to what extent is tunnel length limited by your suggested source mechanism?

ST LAWREnce: In the example we presented we selected the length $L$ of the tunnel to produce a wave with a frequency that is consistent with the $\mathrm{I}-5 \mathrm{~Hz}$ frequencies observed at significant distances from glaciers. As you note for the boundary conditions we applied (i.e. flow terminated at the tunnel outlet with a constant head at the up-stream end), the frequency is inversely proportional to the tunnel length. What we find then is that when we decrease the length of the conduit the frequency increases. In our example the energy radiated as seismic waves is related to the kinetic energy of the moving water column. Reducing the length of the conduit then reduces the kinetic energy that can be transformed to seismic energy, thus the higher the frequency the lower the energy output. When we do very close monitoring (as we did on the Variegated Glacier) we see very-high-frequency signals of $5-30 \mathrm{~Hz}$ which fit our proposed source mechanism.

J. W. GLen: Can I clarify my understanding of your proposal by asking whether I am right in saying that your proposal is basically that the water channel resonates in the hydraulic equivalent of a closed organ pipe?

St LAWRence: For the example we have presented this is precisely correct.

G. K. C. Clarke: A modification of Dr Glen's organ-pipe analogy would be to drill a hole in the side of the pipe as may happen when a bore hole connects to the subglacial drainage network. This would add additional damping to the system. Perhaps Dr Hodge's difficulties in connecting to the subglacial drainage of South Cascade Glacier is an indication that the network has been greatly affected by the earlier successful holes he drilled. In particular, if hydraulic hammering or hydraulic fracturing play a role in expanding the network, the successful bore holes might act as surge tanks and inhibit these mechanisms.

ST LAWRENCE: Assuming that our proposed seismic source is correct then your observation and conclusion would necessarily follow. 